\title{
Variabilidade biológica de isolados do Citrus leprosis virus (CiLV) oriundos de cultivares de laranjeira
}

\author{
Jadier de Oliveira Cunha Junior ${ }^{1}$, Luciana Pozzer ${ }^{2}$, Paulo Sergio Torres Brioso ${ }^{1}$
}

${ }^{1}$ Laboratório Oficial de Diagnóstico Fitossanitário/DEnF/IB/UFRRJ, Caixa Postal 74585, CEP 23851-970, Seropédica, RJ, e-mail: jadier@ufrrj.br; ${ }^{2}$ Ministério da Agricultura, Pecuária e Abastecimento, SFA-SSV RJ.

Parte da dissertação de mestrado do primeiro autor

Autor (a) para correspondência: Jadier de O. Cunha Jr.

Data de chegada: 03/11/2004. Aceito para publicação em: 14/01/2007.

\section{RESUMO}

Cunha Junior, J.O.; Pozzer, L.; Brioso, P.S.T. Variabilidade biológica de isolados do Citrus leprosis virus (CiLV) oriundos de cultivares de laranjeira. Summa Phytopathologica, v.33, n.3, p.294-296, 2007.

A leprose, causada pelo Citrus leprosis virus (CiLV), é uma das principais doenças presentes em pomares cítricos fluminenses. O objetivo deste trabalho foi comparar o quadro sintomatológico desenvolvido por isolados de CiLV obtidos de cultivares comerciais de laranjeira (Lima, Pêra e Seleta), inoculados mecanicamente em Chenopodium amaranticolor, em três diluições. Após cinco a sete dias da inoculação foram observadas lesões necróticas, com pequeno halo clorótico quando observadas contra a luz. O maior número de lesões, nas três diluições, foi obtido do isolado de 'Seleta', seguido por 'Pêra' e 'Lima'. A melhor diluição utilizada para a observação das lesões foi de 1:10. Os resultados demonstram uma possível variabilidade biológica entre os isolados virais e/ou uma menor ou maior replicação viral, dependendo da cultivar, indicando um possível mecanismo de resistência da planta ao vírus.

Palavras-chave adicionais: Citros, leprose, Cytorhabdovirus.

\section{ABSTRACT}

Cunha Junior, J.O.; Pozzer, L.; Brioso, P.S.T. Biological variability of Citrus leprosis virus (CiLV) isolates from sweet orange cultivars. Summa Phytopathologica, v.33, n.3, p.294-296, 2007.

Citrus leprosis, caused by Citrus leprosis virus (CiLV) is one of the major diseases in citrus orchards in the State of Rio de Janeiro. The objective of this study was to compare the development of symptoms on Chenopodium amaranticolor inoculated with CiLV isolates from 'Lima', 'Pera' and 'Seleta' sweet oranges using three different dilutions. Five to seven-days after inoculation, necrotic lesions exhibiting a small chlorotic halo when exposed to the light, were observed. The highest number of lesions developed using the three dilutions was obtained from 'Seleta', an intermediate value from 'Pêra' and the lowest number from 'Lima'. The best dilution for lesions development was 1:10. The results demonstrate a possible biological variability among the virus isolates and/or a lower or higher viral replication, dependent on the cultivar. This indicates a putative mechanism of Citrus resistance to the virus.

\section{Additional Keywords: Citrus, leprosis, Cytorhabdovirus}

A leprose, causada pelo Citrus leprosis virus (CiLV), é uma das principais doenças dos citros (Citrus spp.) no Estado do Rio de Janeiro. Em geral, as laranjas doces (Citrus sinensis (L.) Osbeck.) são suscetíveis, desenvolvendo sintomas típicos, enquanto as tangerinas (Citrus reticulata Blanco), os pomelos (Citrus paradisi Macf.), as toranjas (Citrus grandis (L.) Osbeck) e as cidras (Citrus medica L.) são tolerantes (6). Em laranjeira doce causa lesões em folhas, ramos e frutos, reduzindo a produtividade e o valor comercial da fruta. Os sintomas podem variar de acordo com as cultivares, a região onde ocorre a doença, a fase de desenvolvimento do órgão afetado e diferentes estirpes do patógeno (5).

O objetivo deste trabalho consistiu em comparar o quadro sintomatológico desenvolvido por isolados de CiLV obtidos de três cultivares comerciais de laranjeira cultivadas no Estado do Rio de Janeiro, através de inoculação mecânica em Chenopodium amaranticolor (Coste \& Reyn.).

Amostras foliares de cultivares de laranjeira, com sintomas diferenciados de leprose (Figura 1 A,B,C), foram coletadas nos municípios fluminenses de Carmo ('Lima' e 'Pêra') e de Seropédica ('Seleta'). As áreas lesionadas foram recortadas, pesadas, maceradas e diluídas a 1:5, 1:10, e 1:20 (g/mL) com tampão fosfato de sódio $\mathrm{pH}$ 7.5 acrescido de $0.1 \%$ de sulfito de sódio e celite. O extrato foi inoculado em seis folhas de C. amaranticolor, sendo a folha mais velha enumerada como primeira folha e assim sucessivamente. Como controle negativo foi utilizado somente tampão e abrasivo. As plantas foram mantidas em casa de vegetação e, após sete dias da inoculação, as folhas foram destacadas das plantas e digitalizadas em Scanner de Mesa TCÊ S530 sendo realizada a contagem das lesões.

As plantas inoculadas com os isolados do CiLV das três cultivares de laranjeira apresentaram lesões locais que iniciaram como pontuações 


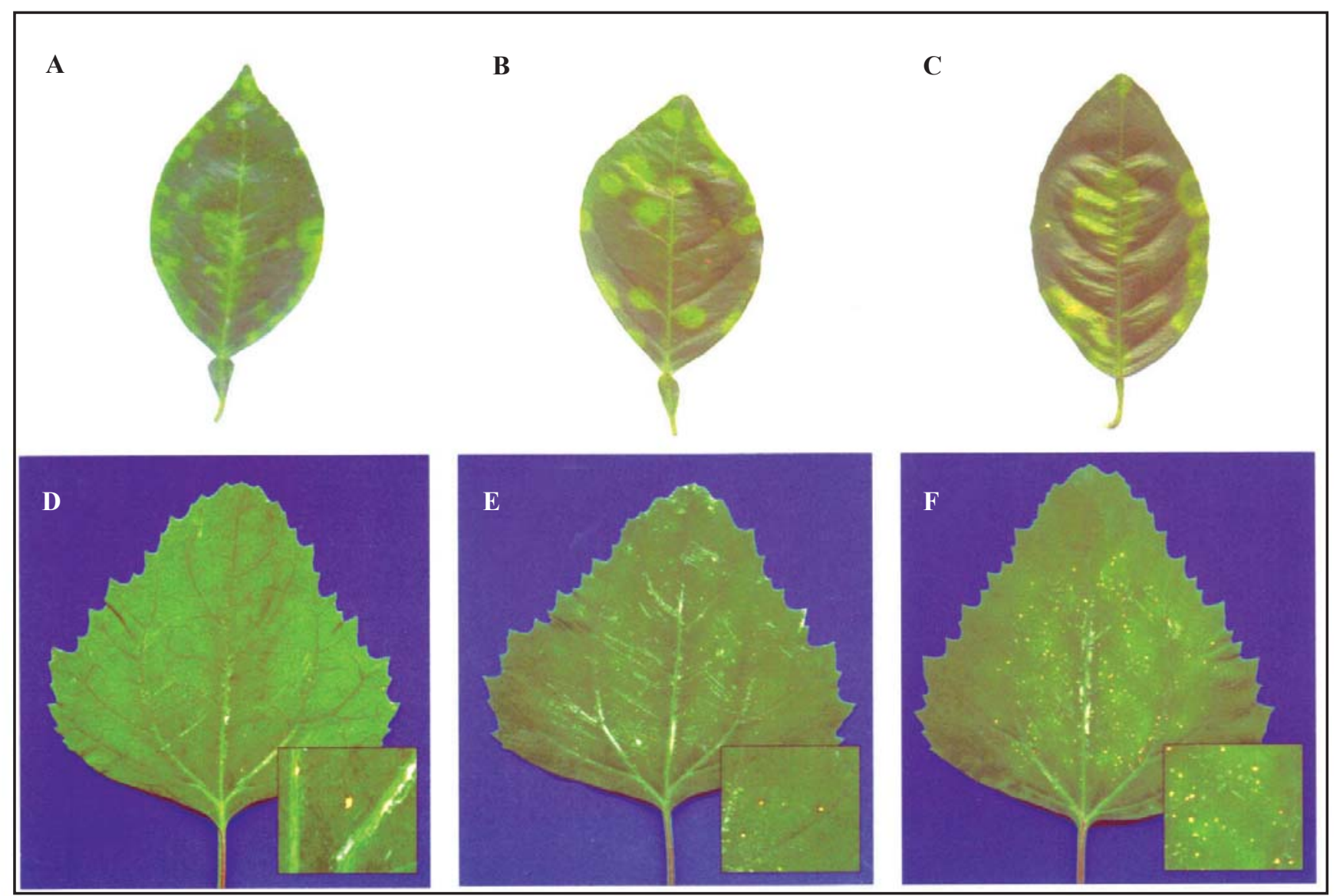

Figura 1. Folhas de laranjeiras apresentando sintomas de leprose dos citros: 'Lima' (A), 'Pêra' (B) e 'Seleta' (C) e folhas de Chenopodium aramanticolor inoculadas mecanicamente na terceira folha, com extratos foliares de laranjeiras, diluídos 1:10 correspondentes a 'Lima' (D), 'Pêra' (E) e 'Seleta' (F)

claras, com aproximadamente $0,75 \mathrm{~mm}$ de diâmetro e pequeno centro translúcido. Após cinco a sete dias da inoculação, tornavam-se necróticas e com halo, este somente observado quando expostas contra a luz. Nenhuma lesão foi observada no controle negativo. De modo geral, as folhas mais novas apresentaram maior número de lesões quando comparadas com as folhas mais velhas (Tabela 1). Em contraposição, trabalhos com isolados paulistas de CiLV obtiveram lesões com 1,5 mm e halo clorótico, e plantas herbáceas mecanicamente inoculadas apresentavam um maior número de lesões em folhas velhas (3). As diferenças observadas nas características das lesões desenvolvidas em C. amaranticolor, bem como na posição das mesmas na planta, pode ser resultado das diferenças dos isolados virais, visto que trabalhos anteriores mostraram que os isolados do CiLV obtidos no Rio de Janeiro são do gênero Cytorhabdovirus (2), enquanto que os isolados paulistas foram registrados como Nucleorabdovirus.

Entre as cultivares, o isolado de CiLV oriundo de 'Seleta' foi o que proporcionou o maior número de lesões, seguido do isolado de 'Pêra'. O isolado de 'Lima' proporcionou um número muito baixo de lesões (Tabela 1). Em relação à diluição do inóculo, o isolado de 'Lima' gerou lesões somente na diluição 1:10, com número constante de lesões entre a $2^{\mathrm{a}}$ e $4^{\mathrm{a}}$ folha (Tabela 1 e Figura 1-D). Para as demais cultivares, todas as diluições propiciaram o surgimento de

Tabela 1. Número de lesões locais por folha de Chenopodium amaranticolor inoculado com extrato foliar obtido de três cultivares de laranjeira apresentando sintoma da leprose dos citros.

\begin{tabular}{|c|c|c|c|c|c|c|c|}
\hline Cultivar & Diluição & $1^{\text {a }}$ folha* & $2^{\mathrm{a}}$. folha & $3^{a}$. folha & $4^{a}$. folha & $5^{\text {a }}$. folha & $6^{\text {a }}$.folha** \\
\hline \multirow{2}{*}{ Lima } & $1: 10$ & 0 & 2 & 3 & 2 & 1 & 0 \\
\hline & $1: 20$ & 0 & 0 & 1 & 0 & 0 & 2 \\
\hline Pêra & $1: 5$ & 8 & 19 & 41 & 9 & 48 & 52 \\
\hline \multirow[t]{3}{*}{ Seleta } & $1: 5$ & 10 & 22 & 25 & 60 & 80 & 110 \\
\hline & $1: 10$ & 58 & 155 & 150 & 195 & 203 & 224 \\
\hline & $1: 20$ & 120 & 280 & 295 & 356 & 416 & 544 \\
\hline
\end{tabular}

* Folha mais velha, ** Folha mais nova. 
lesões nas plantas inoculadas. O maior número de lesões foi obtido do isolado proveniente de 'Seleta', na diluição de 1:20 (Tabela 1). Quanto ao número de lesões, observou-se variação entre a posição das folhas de C. amaranticolor e entre as fontes e as diluições do inóculo. O maior número de lesões obtido do isolado proveniente de 'Seleta' pode ser explicado pelo fato desta cultivar ser altamente suscetível ao CiLV e, desta forma, possivelmente concentrar um maior número de vírions em seus tecidos, sendo 'Pêra' uma cultivar um pouco menos suscetível e 'Lima' mais tolerante ao isolado viral. Diversos autores enfatizam um comportamento sintomatológico diferenciado entre variedades cítricas e a leprose $(1,4,6,7)$, apontando para a existência de diferentes graus de resistência das cultivares. Assim, os resultados obtidos neste trabalho permitem concluir que a determinação do ponto de diluição ideal do vírus para cada cultivar de citros, constitui-se em uma informação importante para o diagnóstico da leprose, por inoculação mecânica. No caso de laranjeira infectada com isolados do CiLV oriundos do Estado do Rio de Janeiro, a melhor diluição empregada foi 1:10, para todas as cultivares testadas (Figura 1D,E,F), apesar da cultivar Seleta ter apresentado maior número de lesões na diluição 1:20. Porém, nessa diluição a contagem das lesões em $C$. amaranticolor foi mais difícil, visto a proximidade entre as mesmas, havendo, inclusive, coalescência das lesões. Recomenda-se que em futuros trabalhos, adote-se a diluição 1:10, pois nessa diluição os isolados das três cultivares propiciaram o desenvolvimento de lesões na planta inoculada, sem a coalescência das mesmas, independentemente da idade da folha. Pode-se ainda concluir que, dependendo da cultivar infectada, haja uma provável variabilidade biológica entre os isolados virais e/ou uma menor ou maior replicação viral, indicando um possível mecanismo de resistência da planta ao vírus.

\section{AGRADECIMENTOS}

À Coordenação de Aperfeiçoamento de Pessoal de Nível Superior (CAPES) pela bolsa concedida ao primeiro autor junto ao Curso de Pós-Graduação em Biotecnologia Vegetal/UFRJ.

\section{REFERÊNCIAS BIBLIOGRÁFICAS}

1. Bitancourt, A. A. Estudos sobre a leprose dos Citrus. I Distribuição geográfica e sintomatologia. II Transmissão natural às folhas. III Transmissão natural às frutas. IV. Experiências de tratamento. Arquivos do Instituto Biológico, São Paulo, v.22, p.161-231, 1955.

2. Brioso, P. S. T.; Cunha Junior, J. O.; De Bonis, M.; Montano, H. G.; Pimentel, J. P.; Faccini, J. I. H. Partial characterization of an isolate of Citrus leprosis virus and occurrence of a mite vector predator in Rio de Janeiro State. In: Conference of the International Organization of Citrus Virologist, XIV., 1998, Campinas, Annals. Campinas: IOCV, 1998. p.167.

3. Colariccio, A.; Lovisolo, O.; Chagas, C. M.; Galleti, S. R.; Rossetti, V. V.; Kitajima, E. W. Mechanical transmission and ultrastructural aspects of citrus leprosis disease. Fitopatologia Brasileira, Brasília, v.20, n.2, p.208-213, 1995.

4. Roessing, C.; Salibe, A. A. Incidência da leprose em variedades de citros. Ciência e Cultura, São Paulo, v.19, n.2, p.303, 1967.

5. Rossetti, V. A leprose dos citros no Brasil. In: Oliveira, C. A; Donadio, L. C. (Ed.). Leprose dos citros. Jaboticabal: FUNEP, 1995. p.1-12.

6. Salibe, A. A.; Tubelis, A.; Salibe, A. B. Suscetibilidade à doença leprose de novas variedades de citros. Summa Phytopathologica, Jaguariúna, v.20, n.1, p.52, 1994. (Resumo).

7. Trindade, M. L. B.; Chiavegato, L. G. Colonização por Brevipalpus obocatus (Donnadieu, 1875), Brevipalpus californicus (Banks, 1904) e Brevipalpus phoenicis (Geijskes, 1939) (Acari: Tenuipalpidae) em variedades cítricas. Laranja, Cordeirópolis, v.11, n.1, p. 227-240, 1990. 